\title{
Espacialização da produção florestal por sortimento de madeira
}

\author{
Isaac Kiszka Sponholz ${ }^{1}$, Paulo Costa de Oliveira Filho' ${ }^{1}$, Edilson Batista de Oliveira ${ }^{2}$ \\ ${ }^{1}$ Universidade Estadual do Centro-Oeste, Campus Irati, BR 153, km 07, CEP 84500-000, Irati, PR, Brasi \\ ${ }^{2}$ Embrapa Florestas, Estrada da Ribeira, km 111, CP 319, CEP 83411-000, Colombo, PR, Brasil
}

\begin{abstract}
"Autor correspondente:
paulocostafh@gmail.com

Termos para indexação:

Sistema de informação Geográfica

Planejamento florestal

Simulação da florestal

Index terms:

Geographic information system - GIS

Forest planning

Forest simulation
\end{abstract}

Histórico do artigo:

Recebido em 16/05/2013

Aprovado em 16/12/2013

Publicado em 31/12/2013

doi: 10.4336/2013.pfb.33.76.533
Resumo - Este estudo apresenta uma alternativa para a espacialização de dados de simulação da produção florestal, por sortimento de madeira, para auxiliar nos processos administrativos e nas tomadas de decisões da empresa florestal. Foi utilizado neste trabalho como sistema de informações geográficas o Sistema para Processamento de Informações Georreferenciadas - SPRING - e de fonte aberta, desenvolvido pelo Instituto Nacional de Pesquisas Espaciais - INPE e para a simulação da produção foi utilizado o Sistema para Prognose do Crescimento e Produção de Plantações de Pinus - SISPINUS - desenvolvido pela Empresa Brasileira de Pesquisa Agropecuária EMBRAPA . A integração do SPRING com o SISPINUS possibilitou a espacialização de dados de prognose de crescimento e da produção por sortimento de madeira, de uma empresa florestal até o ano de 2030, além da possibilidade de planejamento espacial e programação do rodízio de talhões. O sistema implementado apresentou bastante praticidade, proporcionando rápida visualização de informações espaciais sobre produção por sortimento de madeira, além de fornecer informações sobre o controle da rotatividade da produção nos talhões e fazendas da empresa. O sistema permitiu agilidade operacional de informações e pode ser aplicado tanto no suporte administrativo como no planejamento das empresas do setor florestal.

\section{Spatial data simulation of forest production by assortment of wood}

Abstract - AThis study presents an alternative to spatial data simulation of forest production by assortment of wood, to suport in administrative and decision-making in the forestry company. For this study it was used as geographic information system for the System Georeferenced Information Processing - SPRING - and open source, developed by the National Institute for Space Research - INPE and for simulation of production it was used a Prognosis System for Growth and yield of Pinus Plantations - SISPINUS - developed by the Brazilian Agricultural Research Corporation - EMBRAPA. The integration the SPRING SISPINUS allowed the data spatialization and prognosis of growth and yield output by assortment of wood; of a forest company by the year 2030, besides the possibility of spatial planning and programming of the rotation plots. The implemented system had enough practicality, providing rapid visualization of spatial information on production by assortment of wood, in addition to providing information about controlling the turnover of production plots and farms in business. The system allowed operational agility of information and can be applied both as administrative support in the planning of forestry companies. 


\section{Introdução}

O planejamento e administração de plantios florestais ganham cada vez mais importância com o aumento da demanda por produtos de origem florestal. Neste sentido, a avaliação eficiente e precisa dos povoamentos florestais é implícita e decisiva para a tomada de decisões na aplicação de ações silviculturais e de explorações, atendendo sempre aos objetivos técnicos e econômicos de manejo do reflorestador (Cesaro et al., 1994).

O planejamento da produção florestal é a organização estrutural das atividades de produção de madeira através de técnicas analíticas, com o objetivo de se indicar opções de manejo que contribuam da melhor forma para atender aos objetivos do empreendimento e da coletividade (Sanquetta, 1996).

Os sistemas de informações geográficas (SIG) são ferramentas que possibilitam integração de informações de diferentes fontes e formatos, gerando um conjunto de operações e análises altamente eficientes para auxiliar na tomada de decisão e nos processos administrativos das empresas. Dentre os sistemas existentes, o Sistema de Processamento de Informações Georreferenciadas - SPRING, desenvolvido pelo Instituto Nacional de Pesquisas Espaciais - INPE, é uma das várias opções existentes de sistemas de domínio público e de fonte aberta, tendência hoje em várias empresas e governos (Câmara, 1996).

A simulação da produção de plantios florestais é de suma importância para o manejo de povoamentos e o planejamento futuro das empresas florestais. No Brasil, a Empresa Brasileira de Pesquisa Agropecuária - EMBRAPA, em conjunto com a UFPR, desenvolveu o Sistema para Prognose do Crescimento e Produção de Plantações de Pinus - SISPINUS, o qual possibilita a simulação da produção, através da prognose de crescimento e da produção de povoamentos de Pinus $s p$, Esta ferramenta computacional permite a simulação de desbastes em diferentes idades e as estimativas dos sortimentos de madeira em volumes parciais, estimados para cada um dos seguimentos do tronco com dimensões pré-estabelecidas conforme uso na indústria. O modelo utilizado pelo aplicativo baseia-se em funções de distribuição de probabilidades que descrevem as distribuições de diâmetro e altura das árvores do povoamento em diversas idades, sítios e número de árvores por hectare (Oliveira, 1995).
Este trabalho teve como objetivo gerar um modelo de dados espacial resultante da integração de um sistema de informações geográficas e um simulador de crescimento, visando auxiliar as empresas no planejamento da produção florestal, a partir de dados de inventário florestal e mapeamento, e possibilitando consultas e análises com respostas espaciais simultâneas sobre as áreas de produção.

\section{Material e métodos}

\section{Caracterização da área de estudo}

A área de estudo é formada por talhões de várias fazendas do projeto Jaguariaíva, localizadas no Município de Jaguariaiva, PR. Essas áreas pertencem a vários proprietários, mas são todas administradas pela empresa Valor Florestal S/A.

A região está localizada no segundo planalto paranaense com altitude média entre $800 \mathrm{~m}$ a $1000 \mathrm{~m}$, com solos intemperizados do embasamento cristalino, solo argiloso, folhelhos, arenosos álicos e latossolovermelho escuro álico. O clima da região, conforme a classificação de Köppen é do tipo $\mathrm{Cfb}$, com temperatura média anual de $20{ }^{\circ} \mathrm{C}$, com incidência de geadas frequentes no inverno e com precipitação media anual em torno de $1.400 \mathrm{~mm}$. A cobertura vegetal nativa é caracterizada pela Floresta Ombrófila Mista e por vegetação característica do cerrado (Câmara Municipal de Jaguariaíva, 2012).

\section{Metodologia}

Inicialmente foi obtida junto à administração da empresa, a base cartográfica em arquivo no formato shapefile, contendo as unidades de produção (talhões florestais) e os limites das fazendas, assim como dados de inventários florestais realizados nos anos de 2006 e 2009. A base cartográfica fornecida possui informações como talhões com área disponível para plantio, área com capoeira, estradas internas, estradas municipais, lagos, leiras, mato, rede elétrica, reflorestamento, viveiro, açude, afloramento rochoso e araucária. Esses dados contém a distribuição espacial e os limites das 35 fazendas que fizeram parte do estudo.

Os inventários realizados em 2006 e 2009 apresentam informações detalhadas, como: data do plantio; data do inventário; fase de manejo, indicando se houve ou 
não desbaste no talhão; número do talhão; idade do povoamento, que é a forma de entrada dos simuladores; área da parcela; número da parcela; diâmetro a 1,30 m do solo - DAP mínimo; DAP médio; DAP máximo; altura média; altura dominante; área basal; número de árvores por hectare; volume total por hectare e volume total comercial por hectare.

Para a implementação do SIG, foi realizada a importação dos dados que foram classificados e agrupados de acordo com a categoria adequada do modelo de dados. O mesmo foi implementado com as seguintes informações vetoriais: estradas principais, hidrografia, limite das fazendas e limite dos talhões. A etapa seguinte foi a edição vetorial e a geração da topologia dos polígonos, necessárias para o funcionamento do modelo orientado ao objeto. Foram realizados alguns ajustes, considerados normais para o processo de transformação e incorporação de arquivos vetoriais para o ambiente SIG, para evitar a duplicação de linhas e falhas no fechamento de polígonos ou geoobjetos, que representam as unidades produtivas ou talhões florestais. Os dados obtidos foram processados no simulador SISPINUS, o que possibilitou as simulações de produção florestal por sortimento de madeira, utilizando-se a função densidade de probabilidades $S_{B}$ e $\mathrm{S}_{\mathrm{BB}}$ de Johnson. Foi obtida a simulação de desbastes e a separação das estimativas de volumes parciais para seguimento adotado pelo sistema de produção da empresa. Os resultados obtidos foram integrados ao SPRING versão 5.1.8, permitindo assim a espacialização dessas simulações, agrupamento de objetos e consultas por expressões lógicas.

O SISPINUS, versão 2.0, possui um modelo de dados baseado em funções de distribuição de probabilidades que descrevem as distribuições de diâmetro e alturas das árvores do povoamento em diversas idades, sítios e número de árvores e a quantidade de carbono sequestrado por hectare. Para o desenvolvimento do trabalho foram utilizadas as equações já existentes no programa, mas é bom salientar que o aplicativo permite a entrada de outras equações de sítio, volume e sortimento.

Para a simulação da produção por sortimento de madeira e implementação do sistema de informações geográficas, foram definidos os sortimentos de madeira atualmente adotados pela empresa que sediou o estudo (Tabela 1).
Tabela 1. Sortimentos de madeira definidos conforme uso na empresa.

\begin{tabular}{ccc}
\hline Sortimento & Diâmetro $(\mathbf{c m})$ & Comprimento da tora $(\mathbf{m})$ \\
\hline Processo & 8 a 18 & 2,4 \\
Serraria 1 & 18 a 23 & 2,6 \\
Serraria 2 & 23 a 35 & 2,6 \\
Laminação & $>35$ & 2,7 \\
\hline
\end{tabular}

Após a alimentação do banco de dados do modelo implementado no sistema de informações geográficas, foram realizadas diversas consultas para atender ao planejamento de gestão florestal. A consulta através de agrupamento de objetos ou de expressões lógicas viabilizou a obtenção de uma rápida seleção e visualização de objetos (em tempo real) que envolvem uma série de atributos, operações e valor. A Figura 1 apresenta um organograma com a sequência operacional do trabalho para a construção do modelo de dados para a espacialização da produção florestal por sortimento de madeira.

\section{Resultados e discussão}

A seguir, são apresentadas algumas das principais consultas simuladas neste estudo e que atendem às necessidades do dia-a-dia da empresa florestal. De posse do sistema de informações geográficas alimentado com as informações obtidas da simulação da produção por sortimento de madeira, e levando-se em conta as características do uso múltiplo no beneficiamento, pré-definidas pela empresa, foram realizadas consultas por agrupamento de objetos (unidades produtivas ou talhões), conforme a sua produção total e por sortimento ao ano.

Na Figura 2 é apresentada toda a produção espacializada para corte no ano de 2013, primeiro ano da simulação, evidenciando os talhões definidos para desbastes (d) aos 12, 13 e 14 anos e cortes rasos (CR) aos 18, 19, 20, 21 e 22 anos da rotação.

A simulação pode ser realizada ano a ano, indicando os talhões planejados para desbastes (d) e aqueles destinados a corte raso (CR). Esses resultados permitem a visualização da redistribuição dos talhões em relação às intervenções programadas para cada ano. 


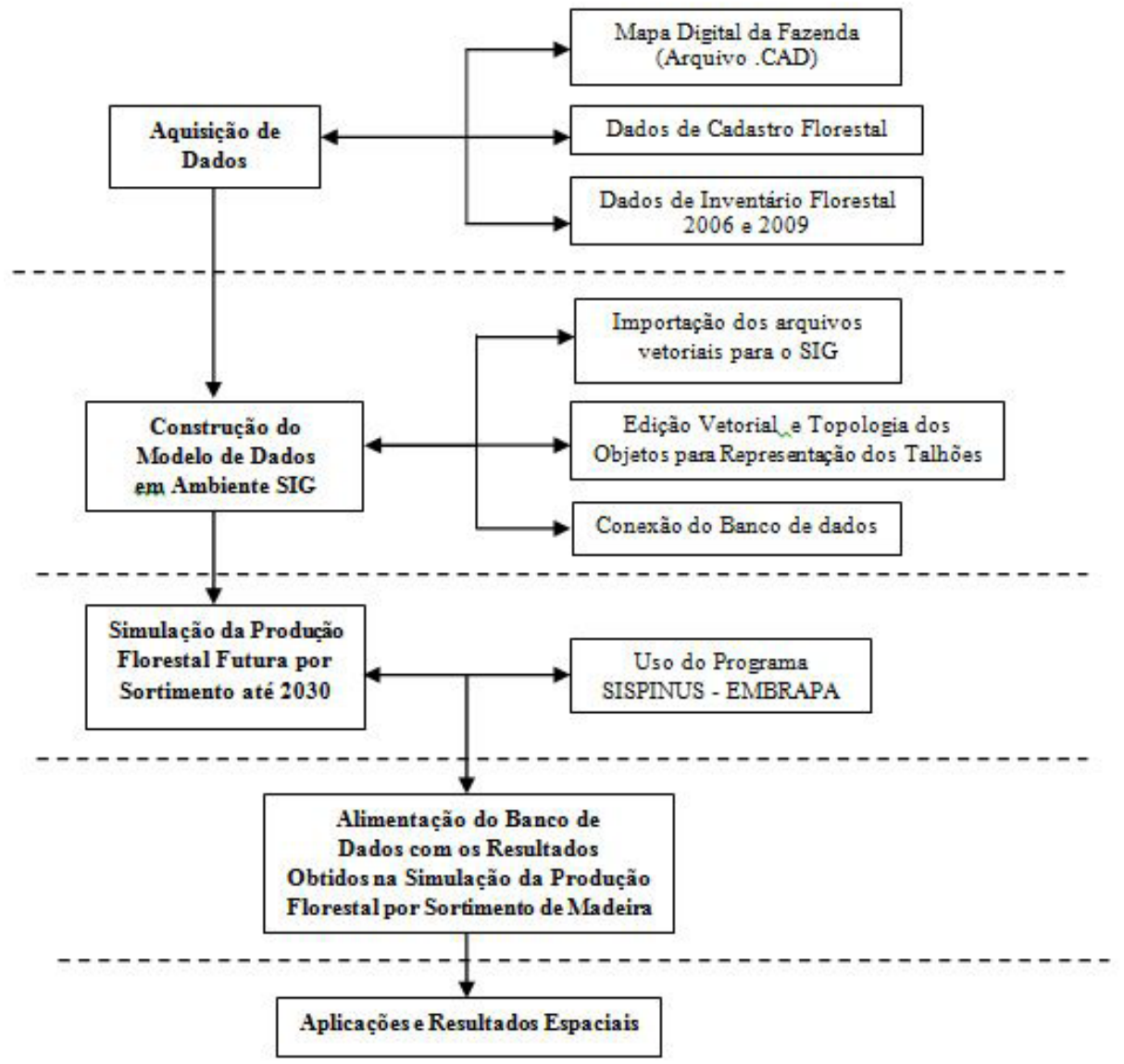

Figura 1. Fluxograma da sequência operacional do trabalho para a construção do modelo de dados.

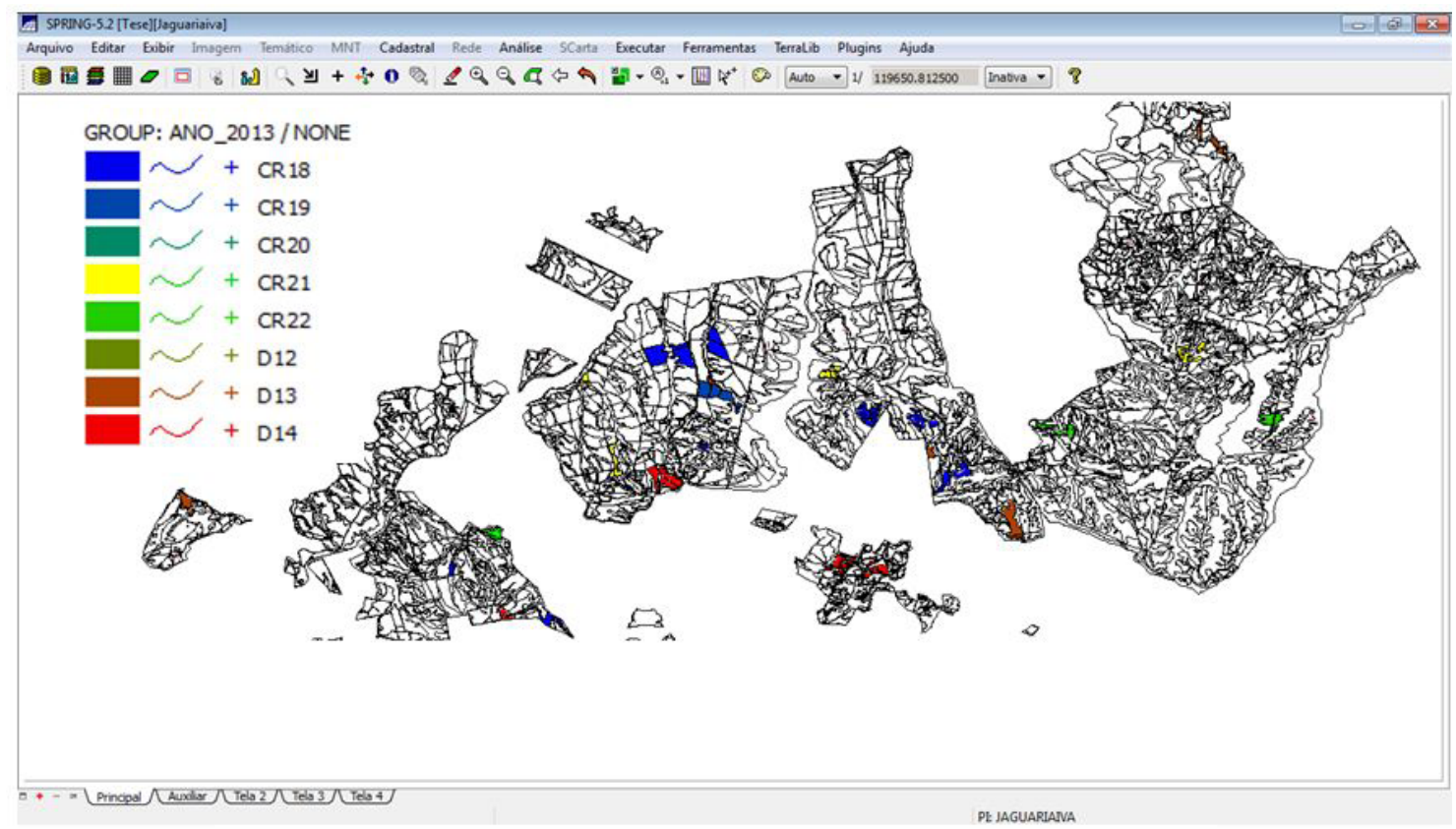

Figura 2. Tela do aplicativo mostrando o resultado espacial da consulta para a produção espacializada para desbaste e corte raso, por talhão, no ano de 2013. 
Desta forma, é possível projetar uma ordenação florestal para vários anos, de modo que as direrentes operações necessárias à colheita e ao escoamento da produção possam ser planejadas com antecedência.

Conforme Burrough (1998), o sistema de informações geográficas é fundamental num processo de espacialização e, na possibilidade de prover análises e modelagens temporo-espaciais. Neste caso específico, nas Figuras
3 a 6 são apresentadas as simulações modeladas por unidade produtiva (talhão) e por ano, conforme o tipo de intervenção. Assim, pode-se representar espacialmente a ordenação da produção florestal da empresa. Como exemplo, na Figura 3 é apresentada a simulação modelada por talhão para o ano de 2015, com desbastes ocorrendo nas idades de 13, 14 e 15 anos, e corte raso aos $18,19,20,21$ e 22 anos.

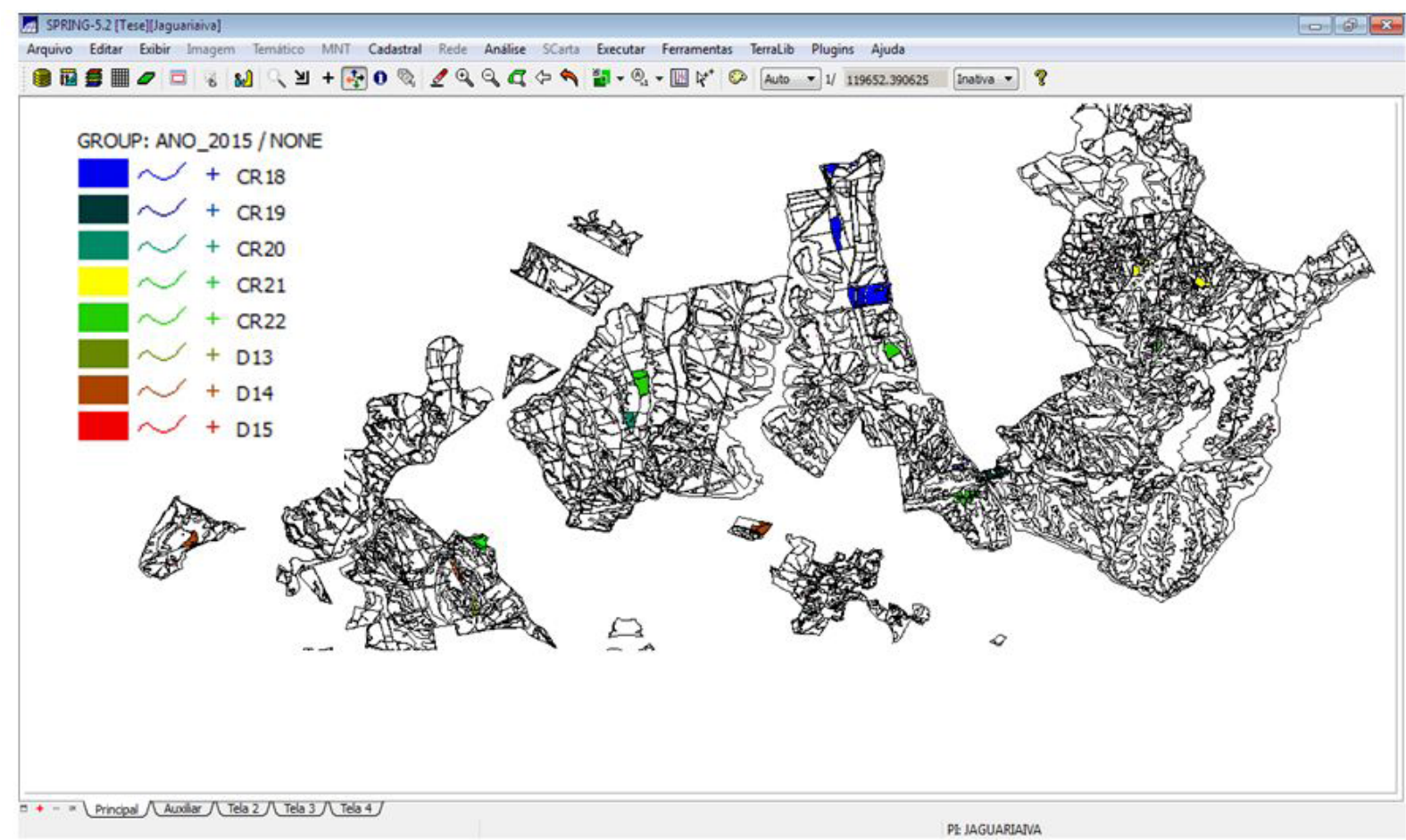

Figura 3. Tela do aplicativo mostrando o resultado espacial da consulta para produção espacializada para corte, desbates e corte raso, por talhão no ano de 2015.

Para otimizar a produção florestal e atender às exigências e necessidades do mercado consumidor é importante ter um bom planejamento das florestas, por meio do controle de sua produção e distribuição espacial, periodicamente. Ressalta-se que na grande maioria das empresas de base florestal, já são bastante conhecidos os processos para prognosticar a produção presente e futura, sendo utilizados para estas finalidades, os software SisPinus (Oliveira, 1995) e o SisEucalipto (Oliveira et al., 2000), disponíveis há mais de uma década. Entretanto, na maioria dos casos, os resultados gerados não apresentam a espacialização simultânea.

Por outro lado, o planejamento florestal considerando a espacialização vem sendo discutido desde o início da utilização do SIG, fato observado durante décadas, pelo grande número de autores que aplicam a tecnologia em seus trabalhos, conforme destacado por Baskent e Jordan (1991).

O maior avanço nesse processo é por meio da obtenção da prognose da produção, incluindo o sortimento de madeira espacializada nas diferentes unidades de produção da empresa. Assim, pode-se tornar o ordenamento e a gestão florestal da empresa mais eficiente, facilitando a tomada de decisão sobre atividades de colheita, manutenção de estradas e aceiros, no planejamento e escoamento da produção. Nesse sentido, não somente o dimensionamento da produção por diferentes sortimentos de madeira, mas também a real distribuição espaço-temporal, ou seja, 
a organização espacial da produção florestal deve ser conhecida e de fácil e rápida visualização. Assim, o planejamento de toda a logística de colheita e transporte já pode ser planejada e operacionalizada, seja através da abertura de novas estradas ou a manuntenção das já existentes.

A organização espacial da produção vem sendo considerada também sob o ponto de vista de cuidados ambientais, importante nos processos de certificação das Empresas. Alguns estudos mostram a expansão de objetivos e restrições visando à produção de madeira e aspectos ambientais, como os de Hof e Bevers (2000). No Brasil, Amaral (2002), trabalhando com povoamentos de eucaliptos, confirmou a hipótese de que a consideração do indicador hidrológico no planejamento de povoamentos florestais afeta significativamente os regimes de manejo, alterando os planos de colheita e o fluxo de produção de madeira.

Com o uso das ferramentas de um sistema de informações geográficas é possível visualizar em tempo real onde e quando cada intervenção deve acontecer, possibilitando assim um melhor planejamento da atividade, o que é de grande importância para o múltiplo uso e uma melhor qualidade da madeira. O modelo de dados espacial implementado pode, consultado através de expressões lógicas matemáticas, fornecer a informação de modo mais direto possível.

Como exemplo, na Figura 4 é apresentada uma consulta para a selecão de talhões com povoamentos de Pinus taeda pertencentes à fazenda Jaguariaíva e que resulte em uma produção para o sortimento LAM (laminação) com pelo menos $15 \mathrm{~m}^{3} \mathrm{ha}^{-1}$ para o sortimento de laminação no ano de 2013, conforme os sortimentos pré-definidos pela empresa e seu uso. Sendo CG000007 a tabela onde foram alimentados os dados de cadastro e produção florestal. A consulta da Figura 8 foi construída através da seguinte expressão lógica:

\section{Expressão Lógica}

(Comentários)

\section{CG000007->FAZENDA CO = 'JAGUARIAIVA'}

.AND.

(Selecione na fazenda Jaguariaíva)

CG000007->ESPECIE = 'PINUS TAEDA' .AND.

(os talhões cuja espécie plantada seja Pinus taeda)

CG000007->LAM_2013 >= 15

(e que apresentem produção igual ou superior a $15 \mathrm{~m}^{3} \mathrm{ha}^{-1}$ para o sortimento laminação no ano de 2013)

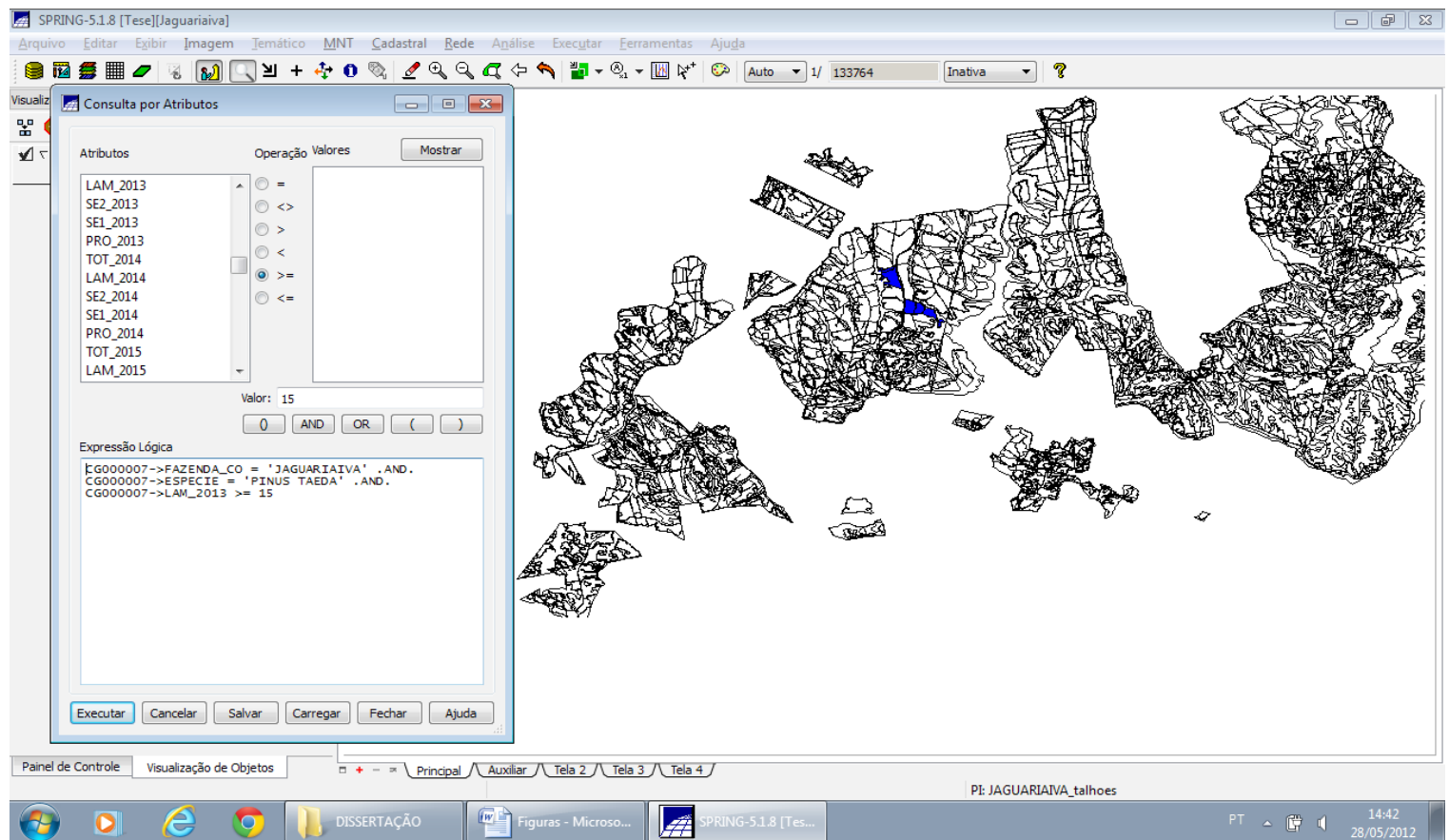

Figura 4. Tela do aplicativo mostrando o resultado espacial da consulta para produção da espécie Pinus taeda, no ano de 2013, acima de $30 \mathrm{~m}^{3} \mathrm{~h}^{-1}$ para o sortimento laminação. 
A partir dessa simulação (Figura 4), observa-se que apenas dois talhões da fazenda Jaguariaíva apresentarão produção mínima de $15 \mathrm{~m}^{3} \mathrm{ha}^{-1}$ para o sortimento laminação no ano de 2013. Desta forma, para atender a este segmento, o gestor pode antecipar programação de suas atividades relacionadas à melhoria ou manutenção dos acessos a estes talhões, como também programar as demais atividades de planejamento de colheita.

A seguir foi construída uma outra consulta, através da seguinte expressão lógica:

\section{Expressão Lógica}

(Comentários)

CG000007->ESPECIE = 'PINUS TAEDA' .AND.

(Selecione os talhões de plantios da espécie Pinus taeda)

CG000007->PRO_2016 > = 30

(e que apresentem produção igual ou superior a $30 \mathrm{~m}^{3} \mathrm{ha}^{-1}$ para o sortimento Processo, para o ano de 2016).

Na Figura 5 é apresentada a distribuição espacial dos talhões com plantios de Pinus taeda que apresentarão produção mínima de $30 \mathrm{~m}^{3} \mathrm{ha}^{-1}$ para o sortimento processo, no ano de 2013.

A consulta da Figura 5 foi construída através da seguinte expressão lógica:

\section{Expressão Lógica \\ (Comentários) \\ CG000007->NUMEROPODA $=3$.AND.}

(Selecione os talhões onde foi realizada a intervenção terceira poda)

CG000007->ESPECIE = 'PINUS TAEDA' .AND.

(e onde a espécie plantada seja Pinus taeda)

\section{CG000007->SE2_2017 > = 180}

(e cuja produção para o sortimento Serraria 2, seja igual ou superior a $180 \mathrm{~m}^{3} \mathrm{ha}^{-1}$ )

Na Figura 5 é apresentada a distribuição dos talhões com produção da espécie Pinus taeda, para o ano de 2017, acima de $180 \mathrm{~m}^{3} \mathrm{ha}^{-1}$ para o sortimento serraria 2, onde foi realizada a terceira intervenção de poda. Assim podese planejar a utilização da produção diferenciada destes plantios, pensando no valor agregado da produção de madeira livre de nós para serraria. Desta forma é possível planejar todas as intervenções que serão realizadas nas unidades produtivas ao longo de seu ciclo. Ocorreu um desbaste aos 9 anos, durante o ano de 2010; ocorrerá um desbaste aos 14 anos, durante o ano de 2015 e ocorrerá corte raso aos 18 anos, durante o ano de 2019. Com esse nível de informação espacializada, torna-se possível ao gestor florestal planejar melhor as atividades de melhoria de estradas ou logística de colheita. Por meio da visualização das informações de produção por sortimento em gráfico do tipo pizza, é possível representar o percentual de produção por talhão nos diversos anos da rotação.

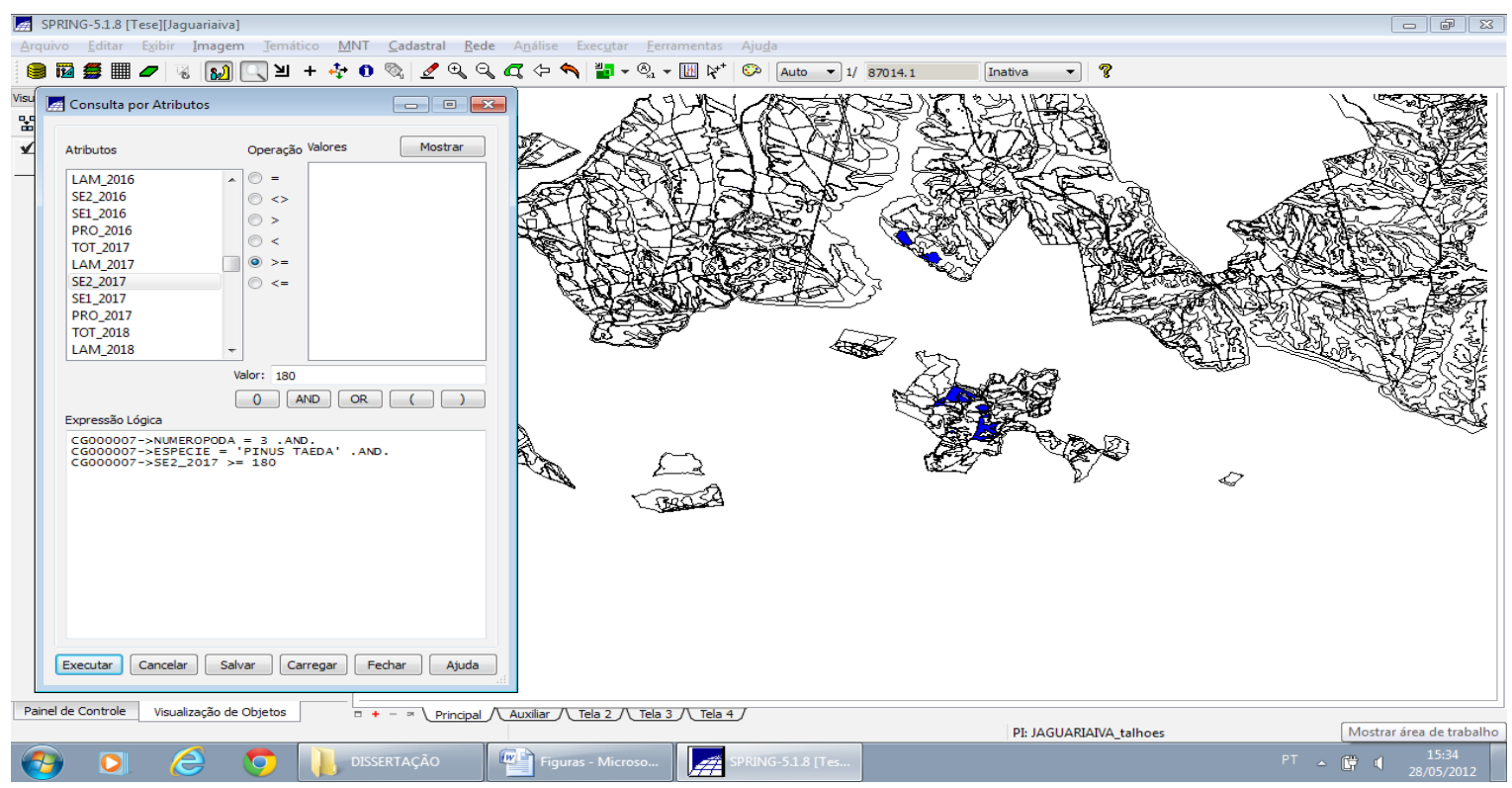

Figura 5. Tela do aplicativo mostrando o resultado espacial da consulta para produção da espécie Pinus taeda, no ano de 2017, acima de $180 \mathrm{~m}^{3} \mathrm{ha}^{-1}$. 
Aconsulta por gráfico de pizza mostra de maneira prática e de fácil e rápida visualização, qual será a situação da unidade produtiva (talhão) para determinado ano. Assim, na Figura 6 é apresentada uma consulta em que é possível visualizar os percentuais de produção por classe de sortimento para o ano de 2020, com destaque para um determinado talhão. Porém, esta operação é feita de forma que seja possível visualizar simultâneamente todas as unidades de produção.

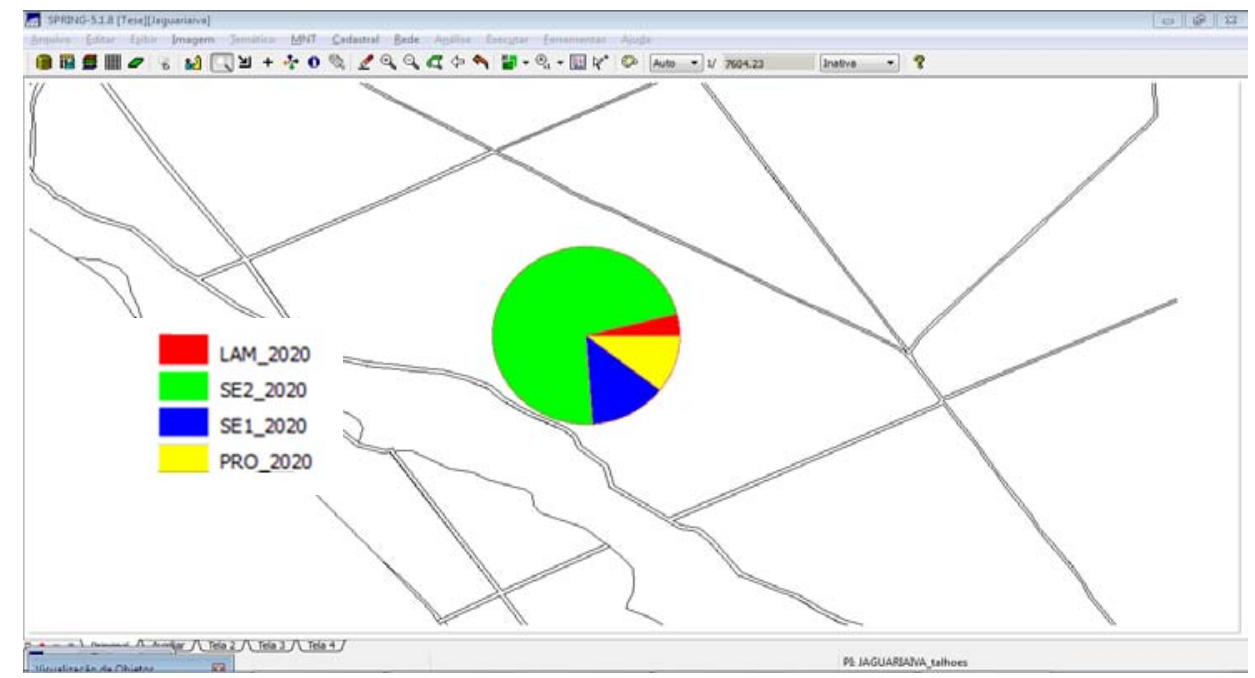

Figura 6. Resultado da consulta para a visualização dos percentuais de produção por classe de sortimento para o ano de 2020, evidenciando um talhão da fazenda Almas, do projeto Jaguariaíva.

Na Tabela 2 são apresentados os valores de produção para o mesmo talhão representado na Figura 6.

Tabela 2. Quantidade e percentual de madeira existente no talhão da figura 15 para cada sortimento.

\begin{tabular}{lcc}
\hline \multicolumn{1}{c}{ Sortimento } & Produção $\left(\mathbf{m}^{\mathbf{3}} \mathbf{h a}^{-1}\right)$ & \% Produção \\
\hline Processo (PRO) & 37,2 & 10,56 \\
Serraria 1 (SE1) & 46,9 & 13,32 \\
Serraria 2 (SE2) & 254,7 & 72,34 \\
Laminação (LAM) & 13,3 & 3,78 \\
Total * & 352,1 & $100 \%$ \\
\hline
\end{tabular}

* Valor efetivo do volume de madeira aproveitável.

Deve-se levar em conta que gerenciar uma unidade de produção requer elevado fluxo de informação, apresentando dificuldades para alocar, organizar, detalhar e interpretar dados. Nas consultas realizadas neste trabalho é demonstrado o potencial de um SIG como ferramenta na gestão florestal, pois a análise espacial e a tomada de decisão são expressas de forma eficiente e ágil. Outras opções para um planejamento florestal espacializado podem demandar conhecimentos de programação linear ou ainda do desenvolvimento de aplicativos específicos. Atualmente há no mercado uma série de aplicativos já estruturados em ambiente SIG, tanto de domínio público quanto de propriedade, que permitem a espacialização de informações tanto de cadastro quanto de simulação da produção.Os resultados apresentados demonstram a facilidade para a espacialização da produção florestal utilizando recursos de um SIG e um simulador de produção florestal que não procede o resultado espacializado.

A tecnologia aqui apresentada se enquadra no que Falcão (2004) destaca como sistemas que permitem a visualização de paisagens florestais através de uma conexão entre um simulador e gerador de alternativas de gestão e modelos de decisão baseados em programação linear e várias heurísticas, através de um gerenciador de dados, por uso de aplicativos como o Smartforest II, Forecast, Atlas, e Simfor.

A praticidade e acessibilidade da tecnologia apresentada contribuem para a viabilização da aplicação de silvicultura de precisão, cada vez mais requeridas pelos produtores. O foco na espacialização já era destacado por Bettinger e Sessions (2003), que afirmaram que o planejamento florestal seria chamado em breve de planejamento florestal espacial tendo como foco as 
atividades do manejo florestal e políticas ambientais. Essa afirmação aponta o rumo do manejo florestal praticamente dependente da informação espacial.

\section{Conclusões}

A partir de dados de inventário florestal de uma empresa do setor, processado em um simulador de crescimento, além de dados cartográficos sobre as fazendas e unidades produtivas, foi possível implementar um modelo de dados espacial em ambiente de sistema de informações geográficas de domínio público, o que possibilitou a espacialização da produção florestal simulada por sortimento de madeira para o presente e para o futuro nas diversas fazendas e talhões florestais por 30 anos de simulação.

A estruturação do modelo de dados espacial baseado em um aplicativo é perfeitamente aplicável a uma empresa do setor florestal, pois as versões atuais desses aplicativos de domínio público são bastante estáveis do ponto de vista operacional.

A partir do sistema implementado do tipo orientado-aobjetos, foi possível realizar uma série de consultas, tanto por agrupamento de objetos como por expressões lógicas boleanas, possibilitando simular cenários do presente e do futuro sobre as fazendas florestais e especificamente sobre as unidades ou talhões de produção considerando os diferentes sortimentos utilizados pela empresa.

O SIG auxilia a gestão da empresa florestal, pois com seu uso é possível que o gestor visualize todas as intervenções que estão ocorrendo e o que está programado para ocorrer nos anos posteriores, facilitando o planejamento de operações direta ou indiretamente envolvidas.

A utilização do SIG e do simulador da produção florestal pode popularizar o planejamento florestal espacializado nas empresas do setor sem a necessidade de envolver conhecimentos de programação ou desenvolvimento de aplicativos. Porém, a liberação de código fonte, principalmente nos SIGs de domínio público, como o SPRING, o gvSIG e o QGIS, também faz desses aplicativos poderosas ferramentas de programação.

\section{Referências}

AMARAL, T. M. Inclusão do controle de deflúvio em modelos de gestão florestal: um estudo no vale do Paraíba - SP. Piracicaba. 2002. 64 f. Dissertação de mestrado. Universidade Espadual de São Paulo.
BASKENT, E.Z., JORDAN, G.A., Spatial wood supply simulation modelling. The Forest Chronicle, Canada, v.67, n.6, p.610-621. 1991

BETTINGER, P.; SESSIONS, J. Spatial forest planning: To adopt, or not to adopt? Journal of Forestry 101 (2), p.24-29 (2003)

BURROUGH, P. A. Principles of Geographical Information Systems for Land Resouces Assesment. Oxford University Press, 194 p. 1986.

CÂMARA, G. et al SPRING: Integrating remote sensingand GIS by object-oriented data modelling. Computers \& Graphics, 20: (3) 395-403, May-Jun 1996.

CÂMARA, G. Sistemas de Informação Para Aplicações Ambientais e Cadastrais: Uma Visão Geral. INPE, São José dos Campos, SP, não datado, $18 \mathrm{p}$ ( texto digitado).

CÂMARA MUNICIPAL DE JAGUARIAÍVA. Disponível em: $<$ http://cmjaguariaiva.pr.gov.br/page.php? $=005>$. Acesso em: 21 de out. 2006

CESARO, A. ; ENGEL, O. A.; FINGER, C. A. G.; SCHNEIDER, P. R. Comparação dos métodos de amostragem de área fixa, relascopia e de seis árvores, quanto a eficiência, no inventário florestal de um povoamento de Pinus sp. Ciência Florestal, Santa Maria, v. 4, n. 1, p. 97-108, jun. 1994.

COUTO, H. T. Z. Sistemas de Informações Geográficas: Aplicações Florestais. IPEF Série Técnica, Piracicaba, 9(28), p 1-18, dez. 1993.

DIAS, A. N.; et al. Emprego de um modelo de crescimento e produção em povoamentos desbastados de eucalipto. Revista Árvore, Viçosa, v. 29, n. 5, p 731-739, set./out. 2005.

FALCÃO, A. 2004. Integração de um visualizador interactivo de paisagens florestais num sistema de apoio à decisão em gestão de recursos naturais - aplicação à Serra da Lousã. Silva Lusitana. $N^{\circ}$ Especial: pp. 89-102.

HOF, J., BEVERS, M. Optimal timber harvest scheduling with spatially defined sediment objectives. Canadian Journal of Forest research, Canada, v.30, n.9, p.1494-1500, 2000.

MIRANDA, J. I. Fundamentos de Sistemas de Informações Geográficas. 2. ed. Brasília, DF: Embrapa Informação Tecnológica, 2010, 425 p.

OLIVEIRA, E. B. ; BERNETT, L. G. ; GRAÇA, L. R. ; MACHADO, S. A. . SisEucalipto - Simulador para o manejo de Eucalyptus grandis. In: Forest 2000, 2000, Porto Seguro. Forest 2000 - Anais, 2000. p. 369-371.

OLIVEIRA, E. B. de. Um sistema computadorizado de prognose de crescimento e produção de Pinus taeda L., com critérios quantitativos para a avaliação técnica e econômica de regimes de manejo. 1995. 134 p. Tese (Curso de Pós-Graduação em Engenharia Florestal) - Universidade Federal do Paraná, Curitiba - PR.

OLIVEIRA FILHO, P.C. ; FIGUEIREDO FILHO, A. ; MEDEIROS, J.; OLIVEIRA, E. B . Implementação de um sistema de informações geográficas para a gestão da empresa florestal. Floresta (UFPR), Curitiba-PR, v. 33, n.1, p. 1-21, 2003.

OLIVEIRA-FILHO, P. C. et al. Implementação de um Sistema de Informação Geográfica para a Gestão da Empresa Florestal., CuritibaPr, 33, p. 31- 52, mar. 2003. 
RAMOS, A. A. Perspectivas Qualitativas e Econômicas da Produção Florestal em Sucessivas Rotações. In: Congresso Florestal Panamericano, 1; Congresso Florestal Brasileiro, 7, 1993, Curitiba. Anais.São Paulo: Sociedade Brasileira de Silvicultura; Sociedade Brasileira de Engenheiros Florestais, 1993. p. 177-189.

ROCHA, C. H. B. Geoprocessamento: tecnologia transdiciplinar. Juiz de Fora - MG, ed.autor, 2000. 220 p.

RODOVANSKI, E. Modelos estáticos para previsão de crescimento de plantações florestais. 2003. 96 p. Dissertação ( Mestrado em Ciência) - Universidade Federal do Paraná, Curitiba, Pr.

ROSE, A. Uma avaliação comparativa de alguns sistemas de informações geográficas aplicadas ao transporte. São Carlos, 2001. 147 F. Dissertação (Mestrado em Engenharia Civil) - Escola de Engenharia de São Carlos, Universidade de São Paulo.
SANQUETTA, C. R. Fundamentos biométricos dos modelos de simulação florestal. Curitiba: Fupef, 1996. 49 f.

SCOLFORO, J. R. Mensuração Florestal 6: Crescimento Florestal 2. Lavras: UFLA/ FAEPE, 1995. 243 p.

SILVA, E. Q. Nova Função densidade de Probabilidade Aplicável à Ciência Florestal. 2003. 98 p. Tese (Doutorado em Ciências Florestais no Programa de Pós-Graduação em Engenharia Florestal) - Universidade Federal do Paraná,Curitiba, PR.

WENDLING, W. T. Sistema computacional e modelagem para Simulação dinâmica da produção florestal. Curitiba: UFPR, 2007. 191 f. Tese (Doutorado em Engenharia Florestal) - Programa de Pós Graduação em Engenharia Florestal, Setor de Ciências Agrárias, Universidade Federal do Paraná, Curitiba, PR. 